\title{
ГРАДОСТРОИТЕЛЬСТВО В СИСТЕМЕ МЕЖОТРАСЛЕВОГО ВЗАИМОДЕЙСТВИЯ И УПРАВЛЕНИЯ
}

\begin{abstract}
Аннотация. На современном этапе развития градостроительства как сферы экономики и сочиума существенным является объективная оценка взаимозависимости и взаимовлияния особенностей экономического развития на градостроительные процессы. Выявление ведущих факторов этих процессов позволит более обоснованно подойти к прогнозированию перспективных направлений изменения расселения, определить предпочтительные в условиях формирования новой экономической модели типы и формы расселения. Актуальность работы обусловлена тем фактом, что роль градостроительства все более будет возрастать в условиях глобализации в связи с потребностью формирования на территории России иентров международного сотрудничества в различных сферах деятельности, соединенных полноценными международными коридорами и трассами различных видов транспорта, передачи энергии, информации, а, возможно, и водных ресурсов. В данной статье дается видение роли градостроительства в стратегии развития России, анализируется современное состояние градостроительства, оценивается значение факторов, влияющих на развитие градостроительной сферь. Автор анализирует варианты преодоления негативных тенденций в сфере развития градостроительства и обеспечения его прогрессивного развития, выделяя в качестве негативных факторов одностороннюю ориентацию структуры экономики, региональную диспропориию в развитии регионов, избыточную кониентрацию ресурсов в центральном регионе и неравноправные отношения цеентра и субъектов, а также недооценка роли и отставание транспортной инфраструктуры и местного самоуправления.
\end{abstract}

Ключевые слова: Градостроительство, Межотраслевое взаимодействие, Структура экономики, Территориальная дифференциация, Внутренний рынок, Транспортная инфраструктура, Город и село, Бюджетная политика, Негативные тенденции, Прогрессивное развитие.

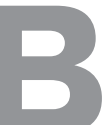

статье, опубликованной в газете «Ведомости» 27 сентября 2013 года, Д. Медведев пишет: «Фактически мы находимся на развилке. Россия может продолжить очень медленное движение близкими к нулевым темпами экономического роста. Или сделать серьезный шаг вперед. Второй путь сопряжен с рисками. Но следование первому сценарию - с мнимой возможностью сохранения уже достигнутого благополучия - еще опаснее. Это прямая дорога к его потере. Дорога в пропасть». Столь жесткая оценка ситуации и возможных перспектив развития страны руководителем Правительства имеет прямое отношение не только к развитию экономики и социальной сферы, но и к сложившейся территориальной организации страны и к ее важнейшей сфере - градостроительство. Не менее существенным является объективная оценка взаимозависимости и взаимовлияния особенностей экономического развития на градостроительные процессы. Выявление ведущих факторов этих процессов позволит более обоснованно подойти к прогнозированию перспективных направлений изменения расселения, определить предпочтительные в условиях формирования новой экономической модели типы и формы расселения.

\section{Роль градостроительства в стратегии развития России}

Если не в столь далеком советском прошлом города и поселки рассматривались как нечто второстепенное, жилое «приложение» к предприятиям, то в современных и тем более в перспективных условиях градостроительная сфера выдвигается в качестве одного из важнейших приоритетов развития страны. ${ }^{1}$

Это обосновывается тем, что реализация новой модели экономического и социального развития возможна лишь при создании благоприятных ус-

${ }^{1}$ В.Я. Любовный Города России: альтернативы развития и управления. М. Экон-информ, 2013. - 614 с. 
ловий для воспроизводства ее главного ресурса - человеческого потенциала, что в свою очередь непосредственно связано с кардинальным повышением качества градостроительной среды и реконструкцией системы расселения. Наряду с формированием благоприятной среды для проживающего населения, важной функцией градостроительства, реализуемой как в самих поселениях, так и в границах локальных и региональных системах расселения становится созданием привлекательных условий для новых сфер и видов экономической и иной деятельности в условиях становления новой модели развития. Важно выделить и еще одну общегосударственную функцию градостроительства, осуществляемую консолидировано с совершенствованием пространственно-инфраструктурной организацией территории страны - обеспечение ее целостности путем укрепления и совершенствования единого экономического, социального, информационного пространства, ее национальной безопасности.

Роль градостроительства все более будет возрастать в условиях глобализации в связи с потребностью формирования на территории России центров международного сотрудничества в различных сферах деятельности, соединенных полноценными международными коридорами и трассами различных видов транспорта, передачи энергии, информации, а, возможно, и водных ресурсов.

\section{Современное состояние градостроительства}

В условиях, когда общество стоит перед выбором стратегических направлений своего дальнейшего развития, важно не только понять причины, приведшие к негативным результатам в развитии городов, но и выработать рекомендации по кардинальному изменению государственной градостроительной политики.

Прежде чем перейти к рассмотрению отмеченных позиций представляется важным дать краткую оценку современного градостроительства и, прежде всего, реализации его важнейшей функции - формирования среды жизнедеятельности.

Недавно опубликованы итоговые данные переписи населения 2010 г. Значительное внимание в них уде- лено жилищным условиям - как одному из главных показателей состояния среды жизнедеятельности. ${ }^{2}$

За период между переписями населения 20022010 гг. общая площадь, приходящаяся на 1 человека, осталась неизменной - 19 кв.м. В относительно комфортных условиях (когда число комнат превышает число живущих) проживает (находится) 34 млн. человек или $25 \%$ населения. Для сравнения: в Германии в подобных комфортных условиях проживает - более 90\% населения, в Испании - более 97\%, в Польше - более $83 \%$, во Франции - более $81 \%$. Ввод общей площади в расчете на 1 жителя нашей страны составил в 2010 г. 0,4 кв. м. Для сравнения, в Китае с конца 2000 г. вводится в год по 1 кв. м., а в последние годы - до 1,4 кв.м. (к сожалению, официальные сведения не найдены). Важна и структура вводимого жилья в Китае: 10\% - элитный фонд, 35\% -бизнес класса, 55\% -эконом-класса.

Обратим внимание на данные по благоустройству жилого фонда в России. 45 млн. человек или 31\% населения страны не имеют газа (вспомним роль страны по запасам и добыче газа!). 41 млн. человек обходятся без горячего водоснабжения (в городах 17\%, в селе - 66\%). У 33 млн. человек туалет - вне жилища (в городах $10,2 \%$, в селе- $62,9 \%$ домохозяйств; и это, как правило, в весьма суровых климатических условиях).

Важно отметить весьма высокий уровень износа существующего жилого фонда. В многоквартирных домах с износом от 30 до 65\% проживает 45 млн. человек. В домах, построенных после 1970 г. проживает почти 83 млн. человек, а построенных ранее 1971 г.52,5 млн. человек.

Заслуживают серьезного внимания сложившиеся к настоящему времени устойчивые тенденции в сфере расселения. Практически за полувековой период (между переписями населения 1959 и 2010 гг.) число сельских поселений сократилось в 2 раза с 294 тыс. до 134 тыс. (Росстат предложил исключить из их состава 19 тыс. сел, в которых нет постоянного населения). Резко ухудшилась структура сельского

\footnotetext{
${ }^{2}$ Фед. служба гос. статистики. Соц.демогр.портрет России. По итогам переписи населения 2010 г. М. Стат. России, 2012. $183 \mathrm{c}$.
} 
расселения - более $1 / 3$ сел насчитывают менее 10 человек. $1 / 3$ сел не имеют выходов к дорогам с твердым покрытием.

Резко усилилась территориальная дифференцииаиция расселения, особенно между столичным регионом и другими регионами страны. Рост региональных диспропоричй - следствие региональной политики (или по большому счету - ее отсутствия), благодаря которой усилилась поляризация развития между относительно благополучной Москвой и все ухудшающимся состоянием большей части других регионов страны. Как показали итоги переписи 2010 г. численность населения страны по сравнению с 2002 г., сократилась на 2,3 млн. чел. (или на 1,6\%) и составила 142,9 млн. чел. При общем снижении численности населения, применительно к различным федеральным округам и субъектам Федерации, вырисовывается достаточно контрастная картина.

Так, среди федеральных округов наибольшие потери населения понесли Дальний Восток - 6\% и Сибирь $-4 \%$. Противоположная картина наблюдается в Москве и Московской области, а также в ряде республик Северного Кавказа. За межпереписной период население Москвы возросло на 11\%, или на 1,1 млн. чел., а в Московской области - на 7,2\% или почти на полмиллиона чел. И если в 2002 г. на долю Москвы и Московской области приходилось 11,7\% населения, то сейчас уже более $13 \%$, т.е. каждый восьмой житель страны живет в столичном регионе (в Москве соответственно 7,15 и 8,1\%, в области - 4,5 и 4,96\%). Хорошо известны противоположные тенденции между относительно благоприятным развитием ряда крупных центров и «прозябанием» на уровне нищенского выживания преобладающей части небольших городов и поселков.

Отмеченное выше состояние жилищно-коммунального хозяйства, сложившихся тенденций формирования городского и сельского расселения - являются отражением более общих процессов в социально-экономическом развитии страны. Особенно существенное влияние оказывают особенности экономического развития, включая финансово-бюджетные отношения.
В этой многоаспектной проблеме, заслуживающей специального полномасштабного освещения, остановимся лишь на следующих позициях.

\section{Влияние структуры экономики страны на особенности расселения, степени благополучия городских и других поселений}

Односторонняя ориентация экономики страны на разработку углеводородного сырья и его экспорт (в значительной мере в необработанном виде) благодаря высоким ценам на нефть и газ, обеспечив на многие годы бюджетно-финансовое «псевдоблагополучие» страны, одновременно породило ряд крупномасштабных негативных последствий:

- «нефтяная игла» практически парализовала многоотраслевое развитие хозяйство страны, определив резкое отставание перехода страны на инновационно-прогрессивную модель экономического развития;

- оно позволило обойтись узким сектором развития экономики, в котором занято лишь 15\% трудовых ресурсов, в связи с чем востребованной оказалась лишь ограниченная группа городов и поселков, связанных с добычей углеводородного сырья, а преобладающая часть городов и градостроительство в целом (с учетом разрушения ВПК) оказались практически на «обочине» развития; исключение составила Москва и отдельные крупные центры, в которых расположены «штабы» естественных монополий, получавшие львиные доли доходов от развития нефтегазодобычи:

- $\quad$ значительные средства, получаемые в результате продажи углеводородного сырья, не были направлены на возрождение реального сектора экономики страны, а привели к резкому расширению закупок значительных по масштабам и разнообразию импортных товаров, в том числе ширпотреба и продовольствия, приведших к закрытию аналогичных производств в стране, лишивших тем самым сотни городов и поселков градообразующей основы их развития, при этом, вновь с особой остротой встала проблема выживания монопрофильных городов; 
- резко усилилась деградация агропромышленного сектора, поставив под угрозу продовольственную безопасность страны, жестко ограничив возможности позитивного развития села и сохранения демографического потенциала.

Указанные процессы, естественно, оказали негативное влияние на формирование среды жизнедеятельности и градостроительства в целом.

\section{Недооценка развития внутреннего рынка страны - одного из приоритетных факторов} возрождения городских и сельских поселений

В настоящее время значительный акцент при определении специализации и перспектив развития регионов и городов делается на выпуск продукции, конкурентной на внешнем рынке. В то же время, значительно меньшее внимание уделяется потребностям внутреннего рынка, который еще длительное время будет нуждаться в продукции, свойственной реальным запросам населения и экономики многих регионов, развитие которых происходит в рамках еще далеких от «высших» экономическим укладов.

Отметим, что существенная переориентация на внутренний рынок, которая, естественно, выходит за рамки проблем градостроительства, будет иметь, как минимум два важных последствия.

Во-первых, она позволит существенно расширить пространство для отечественных производителей, продукция которых не только не уступает, но и нередко превосходит по своему качеству зарубежные товары, заполнивших внутренний рынок. Более активная и в известной степени «агрессивная» политика в рамках цивилизованных отношений, представляется чрезвычайно актуальной в связи с вступлением России в ВТO.

Во-вторых, большая ориентация на внутренний рынок- одно из важных средств стабильного, устойчивого развития экономики страны и снижения зависимости от далеко не всегда предсказуемых негативных проявлений, свойственных мировым кризисам. На фоне широкомасштабного вывоза из страны практически необработанного природного сырья (включая морепродукты) и приобретения изготовленного из него продукции за рубежом, примеры создания отечественных перерабатывающих предприятий носят пока единичный характер. В качестве такого примера следует привести пуск завода «Тобольск-полимер». Приведем выдержки из выступления В.Путина в Тобольске 15.10.2013 г. «По уровню потребления нефтехимической продукции, даже несмотря на рост последних лет, мы все еще в разы уступаем развитым странам... Разумеется, здесь нельзя сидеть и ждать, что что-то само собой, автоматом изменится к лучшему. Нужно формировать и расширять свой национальный рынок, создавать стимулы для широкого использования современных материалов из полимеров. Нужно строить и систему поддержки и наращивания экспорта. Однако пока мы сами вынуждены, как известно, закрывать дефицит по целому ряду позиций за счет импортных поставок. Это прямая упущенная выгода. Пока мы закупаем эти товары, которые вполне могли бы производить сами, из-за границы, как я уже сказал, - это и упущенная выгода, это и налоги, не поступающие в нашу налоговую систему, это не созданные рабочие места, которые мы могли бы создать. Разумеется, само по себе импортозамещение - это не панацея от всего и вся, и, конечно, не всегда нам нужно стремиться к этому импортозамещению. Но там, где это возможно, особенно имея в виду наличие у нас уникальной сырьевой базы, конечно, нужно к этому стремиться. Повторю, мы должны стать хозяевами на собственном рынке». ${ }^{3}$

\section{Об экономических основах взаимодействия города и села}

Одно из главных направлений активизации малых городов связано с повышением их роли в развитии аграрно-промышленного комплекса и сельской местности в цุелом. Это направление должно рассматриваться в контексте решения как минимум двух общегосударственных задач - обеспечения продовольственной безопасности страны и социально-экономического развития сельских территорий.

\footnotetext{
${ }^{3}$ В.В. Путин Выступление на совещании по вопросам развития нефтехимической промышленности. 15.10.2013 г. Официальный сайт Президента России.
} 
В последние годы около $40 \%$ продовольственных ресурсов поступало по импорту, однако, известно, что граница продовольственной безопасности не должна превышать 20\% зарубежных поступлений.

По нашей оценке в недавнем прошлом 3/4 малых городов в той или иной степени были связаны с обслуживанием сельскохозяйственного производства и населения, тяготеющих к ним сельских районов. По расчетам доцента географического факультета МГУ А.И.Даньшина из 2072 малых городов и ПГТ 1571 или 76\% находятся в зоне сельскохозяйственного освоения и могут претендовать на развитие перерабатывающей промышленности.

Рассматривая роль малых городов в развитии сельских районов, необходимо выделить их две главные функции: во-первых, как местных «столиц», обеспечивающих население тяготеющих к ним сел многими видами услуг, такая роль особенно важна в условиях малолюдности преобладающей части сельских населенных пунктов; во-вторых, как центров локальных аграрно-промышленных комплексов, выполняющих разнообразные функции, связанные с производством сельскохозяйственной продукции, ее переработкой, реализацией, организацией необходимых форм финансово-экономической, юридической, технической и иных видов содействия субъектам хозяйствования.

Тем самым малый город, оказывая разностороннюю помощь сельской местности, с одной стороны, приобретает прочные и постоянно возобновляемые функции для своего устойчивого развития, с другой - способствует возрождению сельской местности. При условии восстановления товаропроводящей сети существенно снизится тенденция к натурализации хозяйства и откроется путь для цивилизованного выхода на рынок. Для реального повышения уровня взаимодействия города и села ключевую роль играет развитие транспортной и других видов коммуникационной инфраструктуры.

Таким образом, учет роли небольших городов в развитии АПК, в котором занято около 1/3 населения страны, позволит не только обеспечить ее продовольственную безопасность и, что не менее существенно, сформировать благоприятную среду жизнедеятельности для многих миллионов сельских жителей, сопоставимую по многим показателям с крупными центрами.

Формирование взаимосвязанной системы расселения, при лидирующей роли малых городов, позволит решать и одну из главных проблем развития российского села - нормализацию демографической структуры, включая закрепление молодых специалистов. Разрушение связей между городом и селом стало одной из главных причин, приведших к длительной стагнации сельского расселения.

О важности взаимоувязанного развития небольших городов и сельских поселений свидетельствует зарубежный опыт и прежде всего Китая. В последние годы здесь активное развитие получила производственная интеграция села и города. Как сообщает Всеволод Овчинников, в России пока еще в должной мере не оценен поразительный феномен китайских реформ: сельская индустрия - так называемые волостно-поселковые предприятия. Даже многие предприятия, производящие телевизоры или запчасти для автомашин, строят на дешевой сельской земле и оснащают оборудованием цеха в селах, дабы выпускать там наименее сложные и наиболее трудоемкие детали. А работа у современных станков очень привлекательна для сельской молодежи. Если в прежние времена подсобные промыслы отвлекали людей от сельского хозяйства, то нынешний бум поселково-волостных предприятий стал опорой сельской экономики, главным источником средств для модернизации земледелия и животноводства, создания сельских школ, больниц, коренного улучшения крестьянского быта. Что же в этом опыте может быть поучительным для России? Думаю, прежде всего, это глубокая переработка сельхозпродукции на месте, производственная интеграция сельских предприятий с городскими. А главное-расширение возможностей для трудоустройства в малых городах и поселках. ${ }^{4}$

${ }^{4}$ Овчинников Всеволод. Сельская индустрия как слагаемое успеха китайских реформ. // Российская газета. 2 февраля 2012 г. 


\section{Урбанистика и рынок недвижимости $2 \cdot 2014$}

\section{Влияние финансово-бюджетной политики}

Преобладающая часть городов и других муниципальных образований не имеет ресурсов для своего развития. На протяжении длительного времени их бюджеты носят остро дефицитный характер, подкрепляемый из вышестоящих источников и позволяющих в лучшем случае оплачивать содержание аппарата и некоторые текущие расходы. Провозглашаемые многие годы обещания по перераспределению доходных источников пока остаются не реализованными. А если учесть сложившиеся диспропорции в оплате труда работников бюджетной сферы (применительно к одинаковым профессиям) в столицах и в других городах и муниципальных образованиях, наряду с общим сокращением в последних мест приложения труда, то усиление миграционных процессов, в том числе масштабов маятниковой миграции (ежедневной и еженедельной) становится вынужденной мерой для значительной части населения.

Отмеченная выше особая «притягательность» Москвы обусловлена не только ее благоприятными предпосылками для развития бизнеса и столичным статусом, но и недостатками региональной политики и системой финансово-бюджетных отношений. Немалую роль при этом играет многократное превышение бюджетной обеспеченности в расчете на одного жителя Москвы, по сравнению с другими городами. Если бюджетная обеспеченность (расходная часть) на одного жителя Москвы составляла в 2010 г. 106,1 тыс. руб., то аналогичный показатель в Санкт-Петербурге -70,5 тыс. руб., а в большинстве центров субъектов Федерации он находится в диапазоне от 7 тыс. до 20 тыс. руб. Ради справедливости отметим, что такие города, как Москва и Санкт-Петербург, имеют очень сложное городское хозяйство, требующее более высоких затрат на его содержание, по сравнению с другими городами. Однако вызывает большое сомнение, что его обслуживание является главной причиной столь крупных расходов. ${ }^{5}$

\footnotetext{
${ }^{5}$ Мыльников Дмитрий. Расчетные показатели, по сведению автора, приведены на основе обработки официальных сайтов городов. http://blogs.mail.ru/mail/mylnikov_dm/
}

Как преодолеть негативные тенденции в градостроительстве и обеспечить его прогрессивное развитие?

Отмеченные выше негативные процессы в сфере градостроительства обусловлены, минимум, пятью причинами. Первая. Односторонняя ориентация структуры экономики, лишившая за последние десятилетия многие города и поселки хозяйственной основы развития. Вторая. Усиливающаяся региональная диспропорция между развитием, сырьедобывающих регионов и преобладающей части субъектов Федерации. Третья. Избыточная централизация функций и ресурсов в Москве, а также неравноправный характер отношений между столицей и другими субъектами Федерации. Четвертая. Недооценка роли и хроническое отставание развития транспортной и других видов инфраструктуры, препятствующих формированию национальной экономики и прогрессивной системы городов. Пятая. Недооценка важности местного самоуправления, которое при полноценным его развитии может взять на себя решение большого круга задач, благодаря инициативной и солидарной деятельности жителей городов и сел. Местное самоуправление это не только форма управления в гражданском обществе, это еще и важнейшая экономическая категория, обеспечивающая масштабное снижение затрат государства на создание и поддержание благоприятной среды для миллионов сельских и городских жителей.

Тем самым, как это не печально сознавать, современные представления о роли городов в развитии экономики России находятся на крайне низком уровне. Доказательство тому, - отсутствие полноценной, научно-обоснованной государственной градостроительной политики.

Начнем с того, что формирование взаимосвязанной системы регулирования развития городов и городских агломераций возможно лишь в рамках совершенствования общегосударственной системы управления, федеративных отношений, региональной и муниципальной политики. Такой подход как одно из направлений регулирования развития городов должен базироваться на разработке Генеральной схемы пространственной организации экономики страны и ее 
регионов, Градостроительной доктрины Российской Федерации, Генеральной схемы расселения. При этом принципиальной основой формирования новой модели экономического развития может быть только многоотраслевое хозяйство, ориентированное на внедрение инновационных подходов, сочетающее при этом активные внешнеэкономические связи с последовательным формированием прогрессивных направлений с ориентацией на внутренние потребности и внутренний рынок. Только такая солидарная направленность позволит создать устойчивую основу возрождения основной массы российских городов. Естественно, речь должна не только о возрождении на новой основе реального сектора экономики, но и реализаций потенциальных ресурсов развития в виде возрождения ценного историко-культурного наследия, использования в рекреационных и других целях уникальных природных предпосылок во многих регионах страны, прекращения вывоза в необработанном виде разнообразных природных ресурсов России.

Применительно к управлению социально-экономическим и пространственным развитием регионов, городов и других населенных мест можно говорить о двух принципиально разных подходах, характеризующих управляющее воздействие. Первый подход базируется на жестком иерархическом разграничении компетенции и полномочий между различными по таксономии территориальными уровнями управления. Но признавая его «удобство» для функционирования системы централизованного управления, необходимо видеть и его существенные недостатки. Применительно к городам при подобном подходе из сферы управления исчезает сам объект - город, как единое социальноэкономическое и пространственно-инфраструктурное образование. Тем самым: управление городом как целостным объектом подменяется дробными позициями, рассредоточенным по разным территориальным и ведомственным уровням власти; исчезает главная цель управления городом - содействие реализации воспроизводственных процессов, ориентированных на воссоздание единого городского «организма» и повышение его устойчивости.
Второй подход может быть реализован лишь при децентрализации управления. На современном этапе децентрализации - один из немногих инструментов, способных, как это не парадоксально звучит, обеспечить условия для прогрессивного развития России как государства федеративного типа. Ее реальное единство, способны обеспечить только экономически и социально самодостаточные регионы, обладающие возможностями устойчивого развития и участвующие в общегосударственном территориальном разделении и кооперации труда.

К сожалению, предпринимаемые в последнее время попытки децентрализации управления, носят весьма ограниченный характер. Исходят в значительной мере из узковедомственных интересов, а также из стремления сохранить сложившийся состав министерств и ведомств, сконцентрированных в столице.

Следующее условие формирования государственной градостроительной политики в России - это смещение акцентов в управлении (регулировании) социально-экономическими процессами, в т.ч. в сфере градостроительства, с примата сугубо оперативных решений на сбалансированное сочетание долгосрочных и текущих подходов. Это в значительной мере связано с особенностью городов и регионов как объектов управляемого воздействия, требующих для реализации стратегических решений, базирующихся на долгосрочных прогнозах развития страны, продолжительного периода и мобилизации значительных кадровых, финансовых, материальных и иных ресурсов. Практика свидетельствует, что недоучет долгосрочных последствий принимаемых решений нередко приводит к необратимым результатам негативного характера.

Еще одним важным условием является отладка взаимоотношений органов государственной власти с органами местного самоуправления в городах и других муниципальных образованиях, на основе существенного повышения уровня прямой и обратной связи.

Также представляется крайне актуальном восстановление на новой основе всей системы управления градостроительным процессом. Причем, как по стране, так и в регионах, городах и районах. 
Нельзя также не понимать, что лимитирующим фактором прогрессивного развития градостроительства является ущербная законодательная база. Необходимо безотлагательно приступить к разработке нормативно-правовой системы градостроительной деятельности, с учетом позитивного отечественного и зарубежного опыта.

И, наконец, при всей важности отмеченных выше позиций (естественно, они не носят исчерпывающего характера), главный вопрос - кадровое обеспечение градостроительства и, что не менее существенно, профессиональный уровень участников этой сложнейшей сферы деятельности. Включая руководство федеральных, региональных и местных органов власти. ${ }^{6}$

Важно ввести за правило, что принятие нередко весьма прогрессивных инициатив и решений, предложенных тем или иным ведомством, должно обязательно «просчитываться» по его последствиям, особенно применительно и ощутимом на самом важном для населения уровне - т.е. в городах и других поселениях. Наглядный пример - повсеместный переход на прогрессивные стандарты в образовании, здравоохранении и охране общественного порядка. Масштабный переход на новые стандарты привел к массовому закрытию малокомплектных школ, фельдшерскоакушерских пунктов, первичных пунктов охраны порядка. Такое внешне весьма прогрессивное решение можно было реализовать только при обязательном условии создание всей системы, обеспечивающей транспортную, временную и экономически приемлемую для населения доступность различных видов услуг. В реальности в большинстве случаев системный подход не был обеспечен. Не лишне заметить, что в качестве одного из «привлекательных» аргументов выступала возможность повышения зарплаты остающемуся персоналу благодаря сокращению кадров. Однако общий негативный итог -столь бессистемного подхода - рост обезлюдения и сокращение сельских поселений и «вымывание» активной части населения из городских поселений.

\footnotetext{
${ }^{6}$ Вавакин Л.В. Профессионализм в деятельности главного ар-
} хитектора. М.: ОАО «Московские учебники», 2009.-220с.
Завершая, отметим, что в решении перечисленных проблем нелишне обратиться к опыту Екатериной II по реконструкции системы городского расселения. Реализованный императрицей системный подход, вполне применим для конкретизации приоритетных задач в сфере современного отечественного градостроительства. ${ }^{7}$

Он, в частности, позволяет определиться с этапами реформы градостроительства, включающими, во-первых, анализ состояния и основных проблем формирования систем расселения, как в региональном разрезе, так и по стране. Такому анализу должна предшествовать детальная оценка состояния каждого города и поселка городского типа. Для адекватной характеристики городов необходимо существенно скорректировать регулярно разрабатываемую органами Росстата систему показателей.

Во-вторых, обоснование требований к перспективной пространственной организации страны и к городскому расселению, определяемых переходом к новой модели социально-экономического развития, а также необходимостью совершенствования административно-территориального устройства, обеспечивающего более рациональное функционирование всех основных сфер деятельности, с учетом интересов населения и национальной безопасности России.

В-третьих, разработку Градостроительной доктрины, генеральной и региональных схем расселения, увязанных с долгосрочными прогнозами социально-экономического развития и пространственной организации страны. С развитием магистральной и региональной инфраструктуры. С совершенствованием административно-территориального устройства, а также с прогнозами модернизации финансово-бюджетных отношений и изменениями законодательной основы градостроительства.

В-четвертых, определение этапности разработки и приоритетного перечня проектно-градостроительной документации (схем районных планировок, генераль-

\footnotetext{
${ }^{7}$ В.Я.Любовный О системном подходе к градостроительству: Екатерина 2 и современность. ACADEMJA Архитектура и строительство, 2013 №1; Градостроительная доктрина Российской Федерации (проект), РААСН, Г.В.Есаулов (рук. группы), И.Г.Лежава, В.Я.Любовный, Г.С.Юсин, Д.Ю.Ломакина. М., Экон-информ, 2014.-30с.
} 
ных планов городов и др.), применительно к конкретным регионам, крупным городским агломерациям, городам, взаимосвязанным системам городского и сельского расселения.

В-пятых, разработку методов, инструментария, финансово-экономических и правовых основ, спо- собствующих реализации принятых документов и материалов в сфере градостроительства.

В-шестых, разработку предложений по формированию организационных структур управления градостроительной деятельностью и по совершенствованию подготовки кадров.

\section{Библиография}

1. В.Я. Любовный Города России: альтернативы развития и управления. М. Экон-информ, 2013. - 614 с.

2. Фед. служба гос. статистики. Соц. демогр. портрет России. По итогам переписи населения 2010 г. М. Стат. России, 2012.-183 c.

3. В.В. Путин Выступление на совещании по вопросам развития нефтехимической промышленности. 15.10 .2013 г. Официальный сайт Президента России.

4. Овчинников Всеволод. Сельская индустрия как слагаемое успеха китайских реформ. // Российская газета. 2 февраля 2012 г.

5. Мыльников Дмитрий. Расчетные показатели, по сведению автора, приведены на основе обработки официальных сайтов городов. http://blogs.mail.ru/mail/mylnikov_dm/

6. Вавакин Л.В. Профессионализм в деятельности главного архитектора. М.: ОАО «Московские учебники», 2009.$220 \mathrm{c}$.

7. В.Я.Любовный О системном подходе к градостроительству: Екатерина 2 и современность.

8. Градостроительная доктрина Российской Федерации (проект), РААСН, Г.В.Есаулов (рук. группы), И.Г.Лежава, В.Я.Любовный, Г.С.Юсин, Д.Ю.Ломакина М.:Экон-информ, 2014.-30с.

\section{References (transliterated)}

1. V.Ya. Lyubovnyi Goroda Rossii: al’ternativy razvitiya i upravleniya. M. Ekon-inform, 2013. - 614 s.

2. Fed.sluzhba gos.statistiki.Sots.demogr.portret Rossii. Po itogam perepisi naseleniya 2010 g. M. Stat. Rossii, $2012 .-183$ s.

3. V.V. Putin Vystuplenie na soveshchanii po voprosam razvitiya neftekhimicheskoi promyshlennosti. 15.10.2013 g. Ofitsial'nyi sait Prezidenta Rossii.

4. Ovchinnikov Vsevolod. Sel'skaya industriya kak slagaemoe uspekha kitaiskikh reform. // Rossiiskaya gazeta. 2 fevralya $2012 \mathrm{~g}$.

5. Myl'nikov Dmitrii. Raschetnye pokazateli, po svedeniyu avtora, privedeny na osnove obrabotki ofitsial'nykh saitov gorodov. http://blogs.mail.ru/mail/mylnikov_dm/

6. Vavakin L.V. Professionalizm v deyatel'nosti glavnogo arkhitektora. M.: OAO «Moskovskie uchebniki», 2009.-220s.

7. V.Ya.Lyubovnyi O sistemnom podkhode k gradostroitel'stvu: Ekaterina 2 i sovremennost'. ACADEMJA Arkhitektura i stroitel'stvo, 2013 №1

8. Gradostroitel'naya doktrina Rossiiskoi Federatsii (proekt), RAASN, G.V.Esaulov (ruk. gruppy), I.G.Lezhava, V.Ya.Lyubovnyi, G.S.Yusin, D.Yu.Lomakina M.:Ekon-inform,2014.-30s. 